\title{
The Research of Degradation about 1,2,4-Trichlorobenzene by the Artificial Media in Microbe Enrichment
}

\author{
Dong-ying Xu \\ College of Civil Engineering, Shaoxing University, Shaoxing, Zhejiang 312000, China \\ Correspondence should be addressed to Dong-ying Xu; xudongying@usx.edu.cn
}

Received 19 March 2014; Accepted 1 July 2014; Published 21 July 2014

Academic Editor: You Song

Copyright (C) 2014 Dong-ying Xu. This is an open access article distributed under the Creative Commons Attribution License, which permits unrestricted use, distribution, and reproduction in any medium, provided the original work is properly cited.

Artificial media were used to enrich microbe and improve the water resource quality; therefore trace quantity organic pollutants of 1,2,4-trichlorobenzene were biodegraded. The result of the test showed that, after domestication, the microassociation enriched in the assembled medium could remove corresponding trace quantity organic pollutants in some concentration. When the temperature was 30 degree centigrade, and the $\mathrm{pH}$ was between 6 and 9 , the effect about the removal on trace-quantity-organic pollutants water was the best. A strain of bacteria that could degrade 1,2,4-trichlorobenzene was separated, and its degradation mechanism to 1,2,4-trichlorobenzene was studied. At the same time, the congener trace quantity organic pollutants could be biodegraded. Biofilm after domestication can effectively degrade a certain concentration range of three trichlorobenzenes and the removal effect of HRT $=7 \mathrm{~d}$ was better than the removal effect of HRT $=5 \mathrm{~d}$. It is evident that the trace quantity organic pollutants of 1,2,4-trichlorobenzene in the source water quality from Meiliang Bay in Taihu Lake can be well degraded by enriched microbes on the artificial media.

\section{Introduction}

1,2,4-Trichlorobenzene which was easily biological concentration in water, harmful to human and livestock health, has been priority-listed in the 129 pollutants by USA EPA [1] and will also be included in the "black lists of priority pollutants in water" in our country [2]. Works are reported in chinese and international [3-5]. The aim of this study is to effectively enrich indigenous microorganisms through artificial medium in the lake [6], forming a layer biofilm on the surface $[7,8]$, using the composite filler as carrier forming bacteria and small animal such as the composition of the bioecological protection of water quality improvement technology, to explore the mechanism of this process on water quality improvement.

\section{Test Equipment and Test Program}

2.1. Test Device and Test Process. Test device and test process are shown in Figures 1 and 2, a combination of membrane hanging good packing artificial medium was in the reactor.
Adding trace 1,2,4-trichlorobenzene in the storage tank, storage tank is connected with silicone tube, regulating the flow of a peristaltic pump.

2.2. The Test Instrument and Organic Reagents. $55 \times 45 \times$ $35\left(\mathrm{~cm}^{3}\right)$ test tank; 25WZB1.5-201 nonclogging pump (Shanghai Lanjing Motor Manufacturing Co., Ltd.); $150 \mathrm{~L}$ storage tank with agitator; BT00-300M peristaltic pump, pump head model TZ1515X (Hebei Baoding Lange current company); the oxygen pump; 1,2,4-trichlorobenzene Shanghai Reagent Factory.

2.3. 1,2,4-Trichlorobenzene Degradation Test Scheme. Low concentration of 1,2,4-trichlorobenzene acclimated process lasted 60 days, the hydraulic retention time (HRT) of 5 days, artificial medium was placed in the test tank, in which a test pool adding 1,2,4-trichlorobenzene, another tank as control. At the same time, different locations of the sediment were 


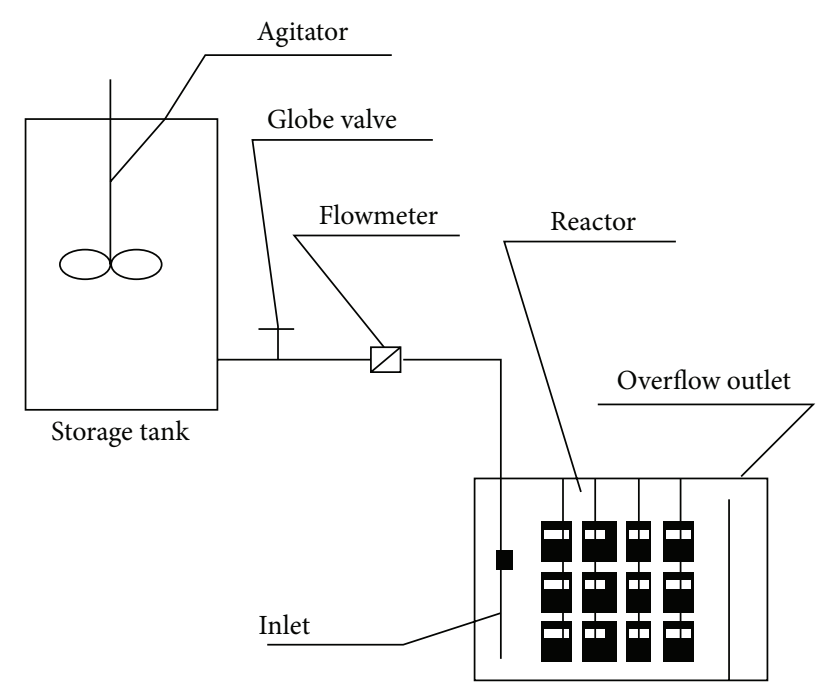

FIGURE 1: Experiment equipment.

often collected in Taihu Lake, with ultrasound of bacteria isolated from the supernatant, added in test pool, to increase the bacterial abundance.

The optimum conditions: trace 1,2,4-trichlorobenzene was sterilized in the conical flask in water, regulating solution for the corresponding $\mathrm{pH}$ value and temperature, and then it was put into the incubator, maintaining the full effect of illumination and oxygen pump sufficient oxygen, determination of degradation effect under different test conditions, every 6 days after determination of organic matter concentration, every time the 3 groups of repeat samples.

Chlorobenzene degrading bacteria test: removing the artificial medium from chlorobenzene degradation test tank, biological membrane above the scrape, and switching to the contained inorganic salts of chlorobenzene, it was cultured in medium with domestication, after repeated streaking from chlorobenzene degrading strain. Taking two conical flasks, one without the addition of glucose, another with glucose, the concentration of 1,2,4-trichlorobenzene was tested every $1 \mathrm{~d}$, $2 \mathrm{~d}, 4 \mathrm{~d}$, and $8 \mathrm{~d}$ water sample.

The main purpose of this experiment was to investigate the effects of concentration and hydraulic retention time of trace organic compounds on the change of the trace organic matter biodegradation conditions. The air temperature was that of the laboratory, by adjusting the rotating speed of the peristaltic pump control flow and inlet and outlet water way from bottom to top. Keeping trace organic matter addition concentration constant, the hydraulic retention time was controlled in 2 days, 4 days, and 8 days. With every change of residence time, each test sample collection pool analysis of trace organic matter content should be stably operated for 3 weeks by GC-MS method; keeping the hydraulic retention time constant for 6 days and changing the concentration of trace organic compounds, each test pool analysis of trace organic matter content had been stablely operated for 2 to 3 weeks by the GC-MS method [9].

\section{Degradation of Chlorobenzene under Static Conditions}

3.1. Temperature. Temperature is an important factor affecting the growth and metabolism of microorganism, according to the results of the organic matter concentration and degradation rate under different incubation temperatures $\left(5^{\circ} \mathrm{C}\right.$, $10^{\circ} \mathrm{C}, 15^{\circ} \mathrm{C}, 20^{\circ} \mathrm{C}, 25^{\circ} \mathrm{C}, 30^{\circ} \mathrm{C}$, and $35^{\circ} \mathrm{C}$ ) and in degradation liquid sampling, the curve has been drawn. Figure 3 shows the different temperature effect on artificial medium 1,2,4trichlorobenzene degradation.

Figure 3 shows that the degradation of 1,2,4trichlorobenzene was strongly sensitive to temperature. In the range of $10-30^{\circ} \mathrm{C}$, with the increase of temperature, degradation rate speeded. It showed that the temperature of $30^{\circ} \mathrm{C}$ was more suitable for the growth of bacteria than $10^{\circ} \mathrm{C}$ and $20^{\circ} \mathrm{C}$. While the temperature was higher than $30^{\circ} \mathrm{C}$, the degradation rate began to decline, the temperature was too high, and the degradation was not conducive to the 1,2,4-trichlorobenzene. When the temperature was $10-30^{\circ} \mathrm{C}$, the reaction speeded with temperature promoting, this was due to the organic volatile increasing, reduced viscosity, water-soluble weakened, bio enhanced availability [10]; it was more important that, with the environment gradually closed to the optimum temperature for microbial growth, microbial enzyme activity was greatly improved, metabolism enhanced, and the degradation rate of 1,2,4-trichlorobenzene speeded up.

3.2. $\mathrm{pH}$. Adjusting the $\mathrm{pH}$ value with $10 \% \mathrm{HCl}$ and $10 \%$ $\mathrm{NaOH}$, they were $4,5,6,7,8$, and 9 , determing the concentration of 1,2,4-trichlorobenzene in 6 days after the sampling of the reaction. Figure 4 was the effect on 1,2,4-trichlorobenzene degradation under different $\mathrm{pH}$.

It can be seen from Figure 4 that, when HRT was 6 days, $\mathrm{pH}$ was 6 9, and the degradation of 1,2,4-trichlorobenzene was quick; when $\mathrm{pH}$ was less than 6 , degradation effect was very poor, and alkaline conditions were more conducive to the growth of microorganism. But when $\mathrm{pH}$ value was higher than 9, the degradation rate decreased; this was because when $\mathrm{pH}$ was greater than 9, zoogloea viscous substances disintegrated, leading to decrease significantly. When the $\mathrm{pH}$ value was 8 , the strain was the best.

3.3. Static Degradation of Chlorobenzene Degrading Bacteria. Figure 5 was chlorobenzene degrading strains isolated after DAPI staining by Zeiss microscope images. Under different substrate conditions of carbon source and chlorobenzene with glucose as carbon source, the degradation curve of chlorobenzene was shown in Figures 6 and 7. It showed that the strain could degrade 1,2,4-trichlorobenzene under the coexistence conditions in glucose and could also degrade 1,2,4-trichlorobenzene under sole carbon source. From the two-curve-line regression analysis, a match with exponential rate model was found. Degradation kinetics equations, respectively, were $y=75.306 e-0.7707 x$ (correlation coefficient $r=0.9803$ ) and $y=24.563 e-0.4364 x$ 


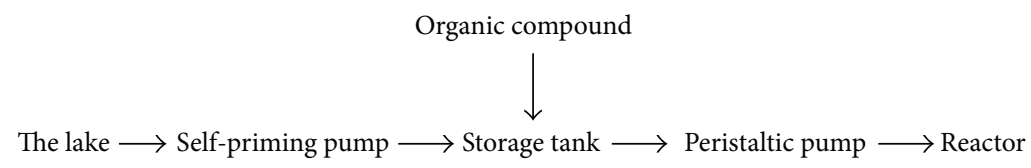

FIGURE 2: Experiment process of degradation about 1,2,4-trichlorobenzene.

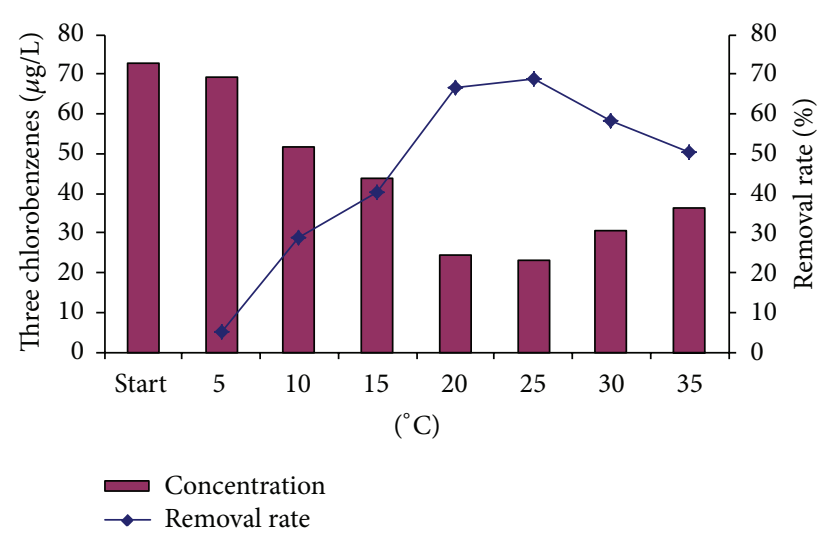

FIGURE 3: Degradation about trichlorobenzene on different temperature.

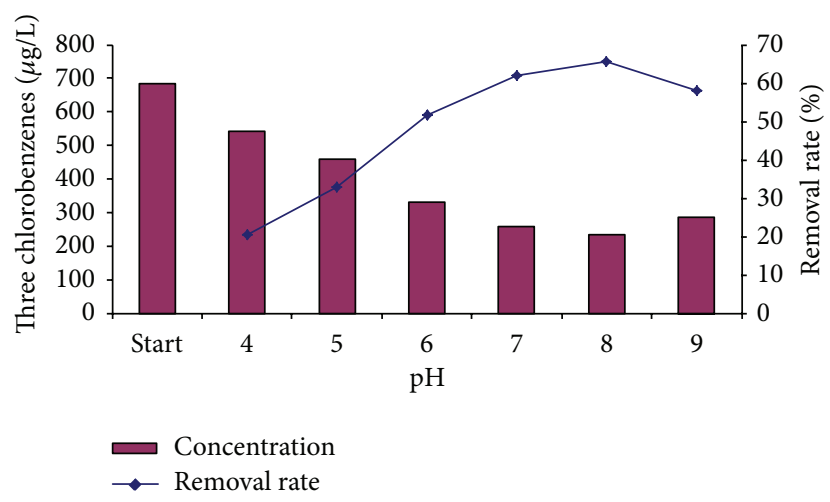

FIGURE 4: Degradation about trichlorobenzene on different $\mathrm{pH}$.

(correlation coefficient $r=0.9397$ ). It obeyed first-order kinetics, consistent with its basic expressions:

$$
\frac{d c}{d t}=-k
$$

the integrals: $C=C_{0} \times e^{-k t}$.

$C_{0}$ was initial concentration and $C$ was instantaneous concentration at any time under the degradation process. $K$ was degradation constant and $t$ was degradation time. 1,2,4-Trichlorobenzene degradation kinetics equation could be seen in Table 1.

From the equation of dynamics, in the addition of glucose conditions, the degradation rate of 1,2,4-trichlorobenzene was greater than in the condition of sole carbon source. From the degradation rate of short half-life, it is indicated that the feeding of glucose was beneficial to the degradation

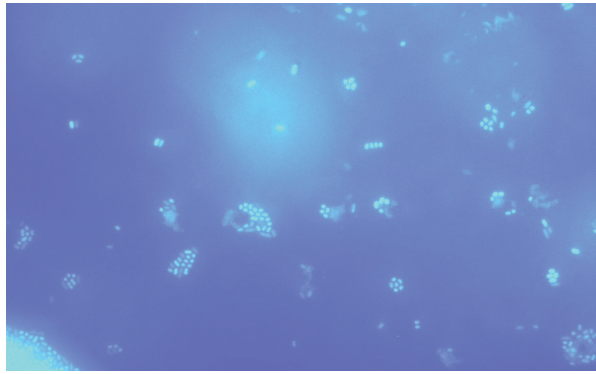

Figure 5: Chlorobenzene-degrading bacteria staining Photo.

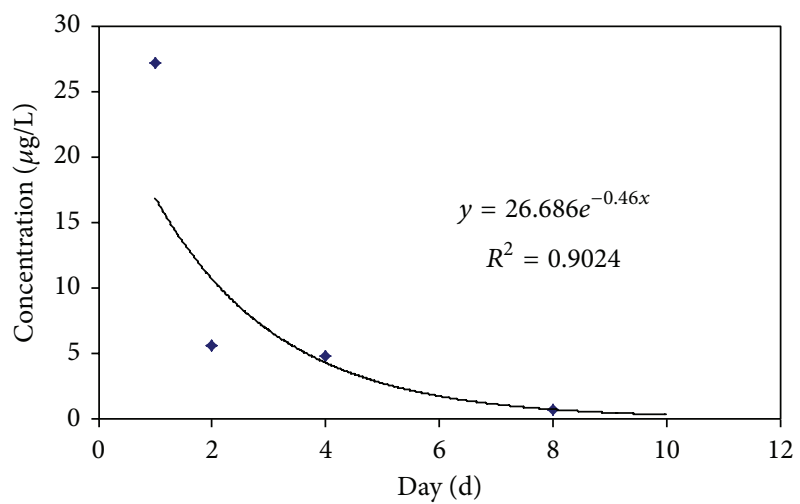

FIGURE 6: With chlorobenzene as carbon source degradation curve.

of the strain on 1,2,4-trichlorobenzene. In the first few days degradation was relatively quick. With the decrease of concentration, the degradation rate slowed down gradually. The results showed that the addition of glucose to 1,2,4trichlorobenzene was benifical. The reason is that microbes can degrade with glucose as substrate [11] and also with 1,2,4trichlorobenzene as substrate, while low concentrations of 1,2,4-trichlorobenzene did not achieve its toxicity tolerance; by adding glucose and the increase in the number of microorganisms, it improved microbial activity and the degradation effect.

\section{Degradation of Chlorobenzene Concentration under Dynamic Conditions}

Combined packing by water of low concentration of 1,2,4-trichlorobenzene acclimated, enrichment microbe can degrade the corresponding organic, so in different conditions it could have some effects on 1,2,4-trichlorobenzene degradation. Selection of different time and different dosage of three trichlorobenzenes was tested, and the residence time was 
TABLE 1: Degradation of 1,2,4-trichlorobenzene dynamics equation.

\begin{tabular}{lccc}
\hline & Kinetic equation & The half-life $t_{1 / 2}(\mathrm{~d})$ & $R$ (correlation coefficient) \\
\hline The addition of glucose & $\ln C=-0.7827 t+4.32$ & 0.90 & 0.9787 \\
Without the addition of glucose & $\ln C=-0.4599 t+3.20$ & 1.59 & 0.9499 \\
\hline
\end{tabular}

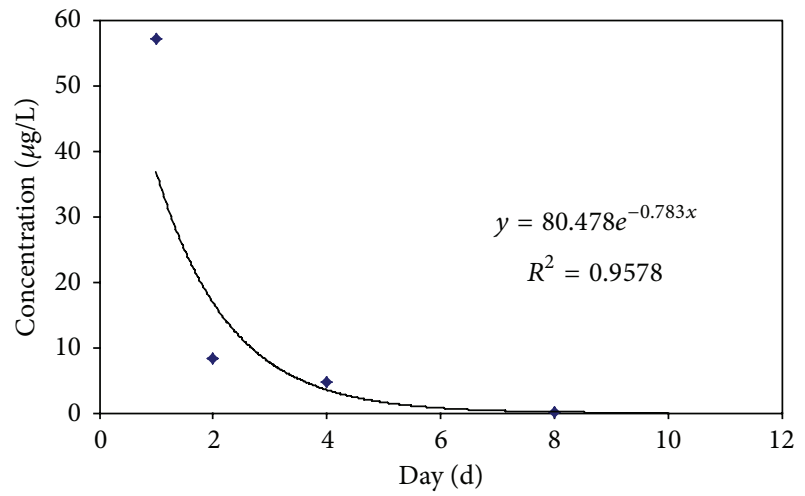

Figure 7: Add glucose chlorobenzene degradation curve.

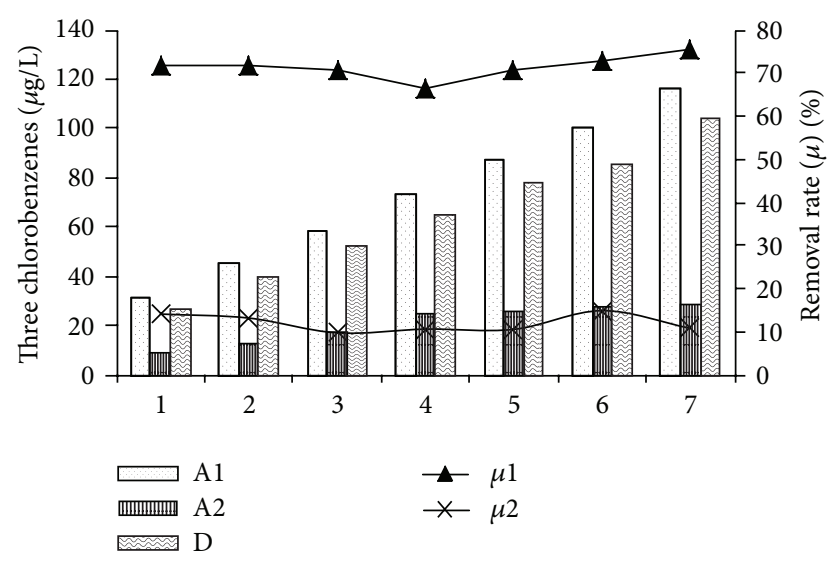

FIgURE 8: Three chlorobenzene degradation of HRT = 7 d. Note: "Al" the influent concentration. "A2" the effluent concentration. "D" the control pool. " $\mu 1$ " the test pool removal rate. " $\mu 2$ " the control pool removal rate.

5 days and 7 days, the trace organic matter was added with concentration increasing, roughly proportional.

It can be seen from Figures 8 and 9, when the residence time was 5 days and 7 days, the removal rate of test pool was relatively stable, in the range of $66.2 \% \sim 75.6 \%$ and $52.7 \%$ $64.2 \%$. The removal rate of control pool can be increased, respectively, in the range of $9.7 \% \sim 14.8 \%$ and $5.8 \% \sim 10 \%$. From the aspect of the water concentration, the effluent concentration of test pool was significantly lower than the effluent concentration of control pool, such that the influent concentration was $31.3 \mu \mathrm{g} / \mathrm{L}$ and $87.6 \mu \mathrm{g} / \mathrm{L}$; in the case of $\mathrm{HRT}=7 \mathrm{~d}$, the effluent concentration of test pool and control pool was $8.8 \mu \mathrm{g} / \mathrm{L}$ and $26.9 \mu \mathrm{g} / \mathrm{L}, 25.5 \mu \mathrm{g} / \mathrm{L}$ and $78.4 \mu \mathrm{g} / \mathrm{L}$. It showed that biofilm after domestication can effectively degrade the certain concentration range of three trichlorobenzenes. The influent concentration was $45.7 \mu \mathrm{g} / \mathrm{L}$ and $116.3 \mu \mathrm{g} / \mathrm{L}$; in

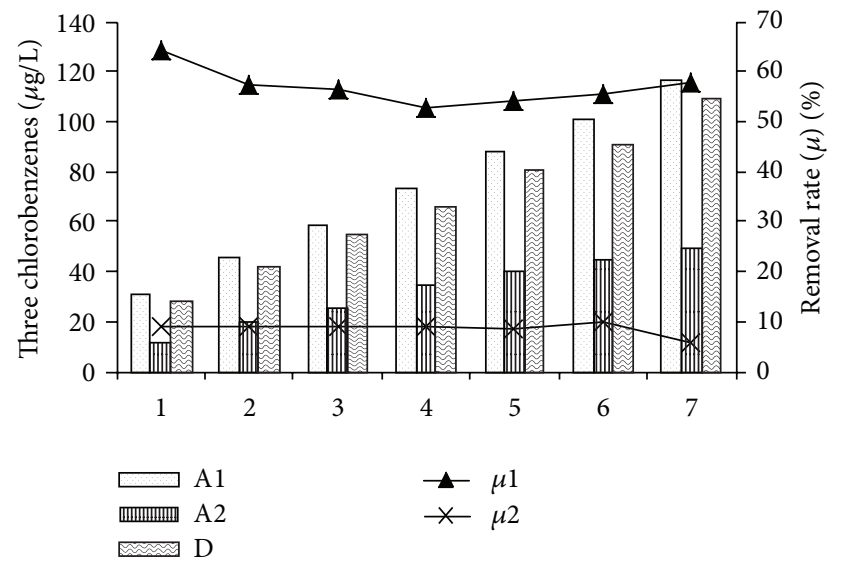

FIGURE 9: Three chlorobenzene degradation of HRT = $5 \mathrm{~d}$. Note: "Al" the influent concentration. "A2" the effluent concentration. " $D$ " the control pool. " $\mu 1$ " the test pool removal rate. " $\mu 2$ " the control pool removal rate.

the case of HRT $=5 \mathrm{~d}$, the effluent concentration of test pool and control pool was $19.6 \mu \mathrm{g} / \mathrm{L}$ and $41.7 \mu \mathrm{g} / \mathrm{L}, 49.3 \mu \mathrm{g} / \mathrm{L}$ and $109.6 \mu \mathrm{g} / \mathrm{L}$. It showed that, in the residence time of 7 days and 5 days, biofilm after domestication can effectively degrade a certain concentration range of three trichlorobenzenes and the removal effect of HRT $=7 \mathrm{~d}$ was better than the removal effect of HRT $=5 \mathrm{~d}$.

\section{Conclusion}

Based on the test results and analysis, we can draw the following conclusions.

(1) The temperature has a great effect on the degradation of organic matter, and the temperature of $25^{\circ} \mathrm{C}$ is more suitable for the degradation of 1,2,4-trichlorobenzene than $10^{\circ} \mathrm{C}$ and $20^{\circ} \mathrm{C}$. When the temperature is higher than $25^{\circ} \mathrm{C}$, the degradation rate began to decline. When the $\mathrm{pH}$ value was 8 , the degradation effect is the best. The bacteria grow more in alkaline conditions than acidic conditions.

(2) Degrading bacteria isolation and culture can effectively degrade 1,2,4-trichlorobenzene with sole carbon source utilization of chlorobenzene but also in the addition of glucose conditions. Dynamic analysis shows that codegradation may improve the effect of biodegradation of trace organic compounds.

(3) Biofilm after domestication can effectively degrade a certain concentration range of three trichlorobenzenes and the removal effect of HRT $=7 \mathrm{~d}$ was better than the removal effect of HRT $=5 \mathrm{~d}$. 


\section{Conflict of Interests}

The author declares that there is no conflict of interests regarding the publication of this paper.

\section{Acknowledgment}

This research was supported by the National HighTechnology Research and Development Program (“863" Program) of China (no. 2002AA601011).

\section{References}

[1] J. Rongping, L. Xiwu, and L. Xianning, "Performance of artificial medium for removing nutrients in eutrophic water," Lake Science, vol. 19, no. 1, pp. 39-45, 2007.

[2] D. Xu and X. Lu, "The experiment research of degradation of 1,2,4 -trichlorobenzene by microorganism," Journal of Nanjing Normal University (Engineering and Technology Edition), vol. 7, no. 4, pp. 55-58, 2007.

[3] Y.-M. Li and R. Ban, "Current pollution situation and research progress of persistent organic pollutants in water environment of China," Guizhou Agricultural Sciences, vol. 39, no. 1, pp. 231235, 2011.

[4] X. Zhan and X. Lv, "Advances of studies on biodegradation of persistent organic pollutants," China Water \& Wastewater, vol. 22, no. 22, pp. 10-12, 2006 (Chinese).

[5] J. R. Zimmerman, U. Ghosh, R. N. Millward, T. S. Bridges, and R. G. Luthy, "Addition of carbon sorbents to reduce PCB and PAH bioavailability in marine sediments: physicochemical tests," Environmental Science and Technology, vol. 38, no. 20, pp. 5458-5464, 2004.

[6] R. Cresson, H. Carrère, J. P. Delgenès, and N. Bernet, "Biofilm formation during the start-up period of an anaerobic biofilm reactor-impact of nutrient complementation," Biochemical Engineering Journal, vol. 30, no. 1, pp. 55-62, 2006.

[7] Y. M. Cho, D. W. Smithenry, U. Ghosh et al., "Field methods for amending marine sedim entwith activated carbon and assessing treatm enteffectiveness," Marine Environmental Research, vol. 64, no. 5, pp. 541-555, 2007.

[8] P. B. Mcleod, M. J. van den Heuvel-Greve, R. M. Allen-King, S. N. Luoma, and R. G. Luthy, "Effects of particulate carbonaceous matter on the bioavailability of Benzo[a] pyrene and 2, 2',5, $5^{\prime}$-tetrachlorobiphenyl to the clam, Macoma balthica," Environmental Science \& Technology, vol. 38, no. 17, pp. 4549-4556, 2004.

[9] H. Tang, S. Wu, and J. Qian, "A discussion on the determination of PCBs," Shanghai Environmental Sciences, vol. 29, no. 3, pp. 132-136, 2010.

[10] G. Wen, "Isolation of chlorobenzene-degrading stain and its degradation conditions," Amino Acids \& Biotic Resources, vol. 31, no. 2, pp. 1-3, 2009.

[11] S. Leng, F. Wei, and L. Zhang, "Identification and biodegradation characteristics of a novel chlorobenzene-degrading bacterial Strain," Environmental Science \& Technology, vol. 34, no. 2, pp. 6-11, 2011. 

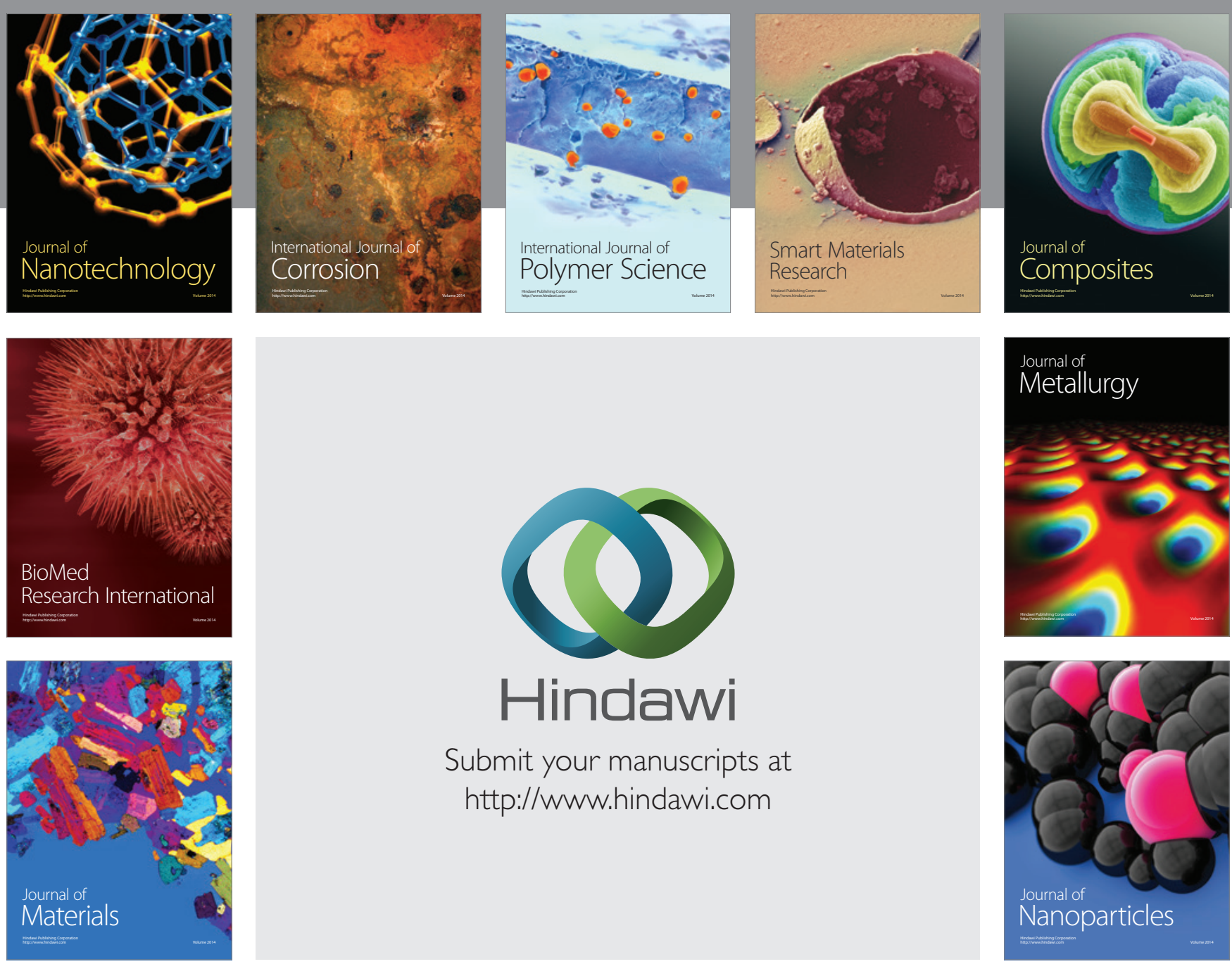

Submit your manuscripts at http://www.hindawi.com
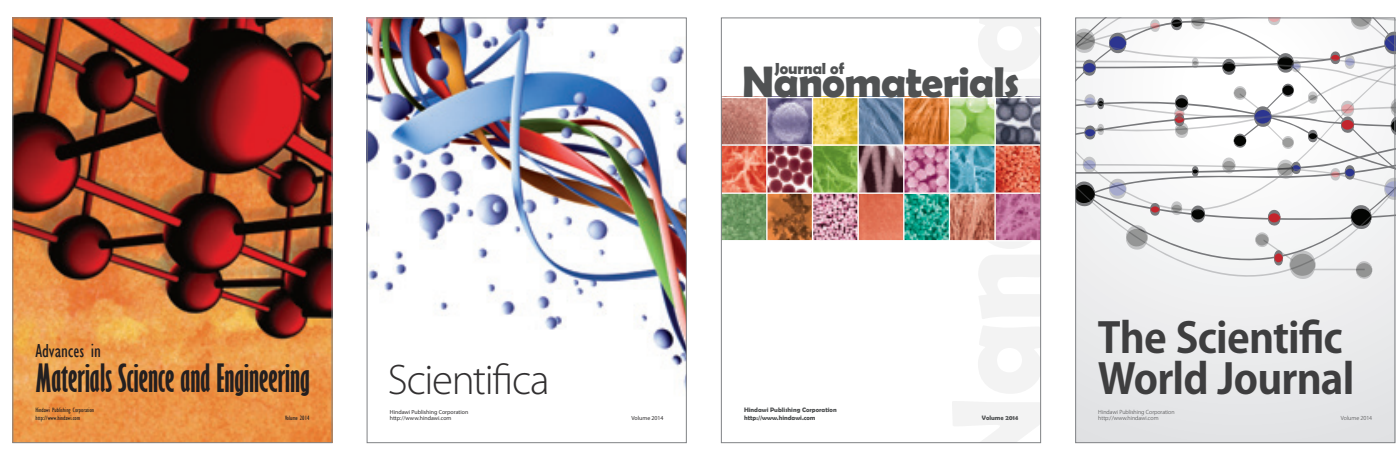

\section{The Scientific World Journal}
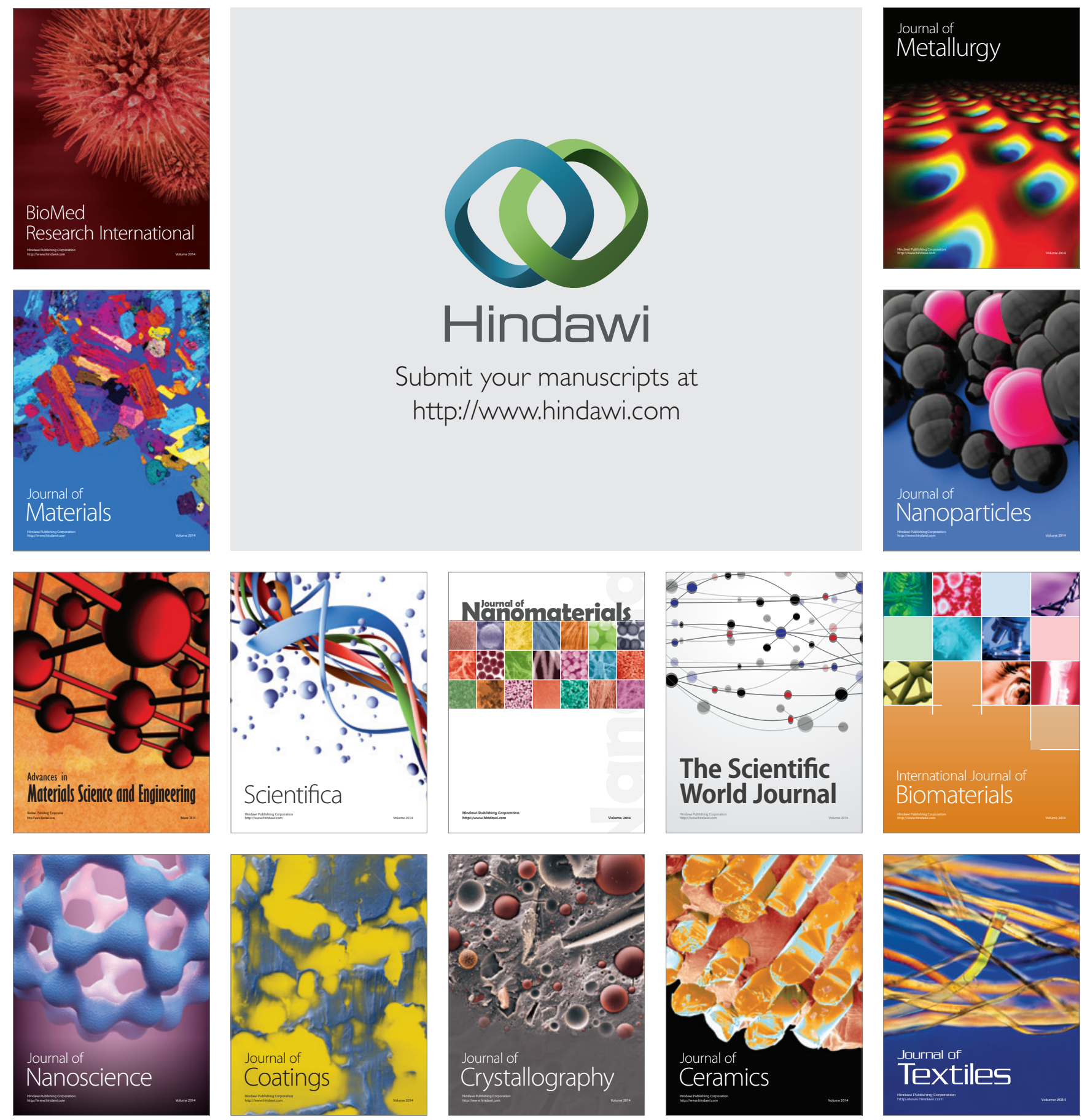